\title{
Triatomídeos da Guiana Holandesa. Redescrição de Panstrongylus lignarius (Walker, 1873) (*)
}

\author{
por \\ Herman Lent
}

(Com nove figuras no texto)

A fauna dos hemipteros hematófagos da familia Triatomidae na Guia na Holandesa é bem reduzida e as referências até o momento existentes são pouco precisas.

A primeira indicação é dada em 1788 , por STOLL ao referir as espécies Triatoma rubrolasciata e Triatoma maculata que chamou, respectivamente, de "La Punaise Mouche de Surinam" e "La Punaise Mouche bigarrée". A outra citação pertence a STAL, em 1859, ao referir Panstrongylus geniculatuls como existente em Surinam. Depois, as citações são todas sob a rubrica geral de Guianas, enquanto PINTo, em 1925, refere Rhodnius prolixus no indice, mas no texto indicando a espécie nas Guianas.

Neiva E Lent, em 1936, dão somente a existência de $P$. geniculatus e em 1941 acrescentam $T$. maculata e $R$. prolixus.

As indicações exatas, entretanto, impõcm que se considere como referidas, até o momento, naquele pais as seguintes espécies:

Triatoma rubrofasciata (DE GeER, 1773).

Triatoma maculata (ERICHSON, 1848).

Panstrongylus geniculatus (LATREILle, 1811).

às quais acrescentamos outras duas, Panstrongylus lignarius (WALkER, 1873) e Rhodnius pictipes STAL, 1872, que recebemos recentemente com uma pequena coleção de hemipteros gentilmente enviada pelo Dr. D. C. GeIJskes, entomologista da "Agricultural Experiment Station", em Paramaribo ( $R$. pictipes representado por um exemplar macho, capturado em Paramaribo, atraido pela luz, em 15-6-41, por Geijskes).

Panstrongylus lignarius é uma espécie muito pouco trabalhada e da qual não existem figuras publicadas, tendo sido referida até agora na Guiana Inglesa e no Norte do Brasil; alem disso, é espécie próxima de Panstrongy-

* Recebido para publicação a 29 de maio e dado à publicidade em junho de 1943 . 
lus humeralis (Usinger, 1939) da qual possuimos para exame o alótipo fêmea. Isto nos levou a publicar o presente estudo, redescrevendo aquela espécie, caracterisando as principais diferenças morfológicas que esta última possue e adicionando figuras elucidativas e a bibliografia existente.

\section{Panstrongylus lignarius (Walker, 1873) PinTo, 1931}

\section{(Figs. 1-6)}

Conorhinus lignarius WaLKer, 1873, pág. 17.

Eratyrus lignarius Lethierry E Severin, 1896, pág. 117.

Conorrhinus lignarius Champion, 1899, págs. 206, 210.

Lamus lignarius Distant, 1902, págs. 191, 192.

Triatoma lignarius NeIVA, 1911, pág. 461.

Triatoma lignaria NeIva, 1914, págs. 7, 46-47.

Triatoma lignaria Del PONTE, 1921, págs. 161, 177.

Triatoma lignaria Hussey, 1922, pág. 116.

Triatoma lignaria Pinto, 1925, págs. 67, 99.

Triatoma lignaria Del Ponte, 193ú, págs. 878-880, 917.

Panstrongylus lignarius PINTO, 1931, págs. 51, 116.

Panstrongylus lignarius HASE, 1932, pág. 599.

Panstrongylus lignarius Neiva E Lent, 1936, págs. 172. 185.

Mestor lignarius Usinger, 1939, págs. 34, 39-40.

Panstrongylus lignarius C. Lima, 1940, pág. 196.

Panstrongylus lignarius Lent \& Pifano, 1940, pág. 631.

Panstrongylus lignarius NeIva E LENT, 1941, págs. 79, 89, 91.

Panstrongylus lignarius Rodrigues $\mathcal{E}$ Mello, 1942, pág. 78.

Comprimento - o $30 \mathrm{~mm}$; oิ $25 \mathrm{~mm}$.

Largura - (ao nivel do pronoto) $q 8 \mathrm{~mm}$, of $7 \mathrm{~mm}$; (ao nivel do abdome) o $11 \mathrm{~mm}$, of $8 \mathrm{~mm}$.

Observado pela face superior, o inseto tem cor geral castanho muito claro desde o torax até o último segmento abdominal, notando-se manchas negras esparsas, perfeitamente visiveis a olho nú, que formam desenhos caracteristicos. A cabeça tem cor nitidamente castanha, as patas e a parte inferior do inseto possuem colorido castanho ferrugineo. Todo o corpo é fracamente revestido de pêlos muito curtos, que só se tornam mais aparentes nas patas e nas antenas. E' muito nítida a diferença de colorido: enquanto o dorso é castanho claro, a face ventral é nitidamente enegrecida, ferrugínea, da mesma cor que o rostro.

Cabeça de colorido castanho, curta, menor do que o pronoto na linha mediana, esparsamente revestida de pequenos pêlos dourados, praticamente inaparentes; região anteocular mais ou menos tão comprida quanto a post-ocular mais a inter-ocular. Tylus bem acentuado, elevado, separado da fronte por uma rugosidade transversal, alargado na base. onde, de cada lado, notam-se dois tubérculos parafrontais bem nítidos; jugae ao lado do tylus, em plano inferior a ele, afilando para diante onde atinge o nivel do ápice do tylus. Fronte larga, com uma linha mediana de pequeninas rugas transversais, que também se 
encontram ao lonyo do tylus formando uma faixa de colorido um pouco mais escuro. Região post-ocular cuita e larga. Olhos salientes, bem afastados superiormente, quasc unidos na face inferior da cabeça, cada olho tendo de largura cerca de $2 / 3$ da aistância interocular. Ocelos grandes, muito aparentes, salientes, colocados próximo dos olhos $c$ atrás deles, mas implantados mais próximo da linha mediana em tubérculos também salientes que nascem ao nivel do margem posterior da cabeça, dirigem-se para diante e obliquamente para fora. Tubérculos anteniferos implantados logo adiante dos olhos. abaixo e ao lado dos tubérculos parafrontais, de colorido castanho como a cabeça, porem mais claro que o do primeiro artículo antenal, quase sem cerdas e sem a saliência apicál externa. Antenas pouco pilosas, longas; o primeiro artículo é de colorido castanho escuro quase preto, possue poucos pêlos pretos, é grosso, mas a sua porção basal é mais delgada e atinge o ápice da cabeça; segundo articulo tambem castanho escuro, mais delgado do que o primeiro, porem com maicr número de cerdas pretas alongadas, alem de pequenos pêlos dourados, possue quase três vezes o comprimento do primeiro; terceiro artículo mais claro (pardacento) e bem mais delgado do que os anteriores, um pouco menos comprido do que o segundo e provido de pélos dourados abundantes e cerdas pretas maiores aguçadas e esparsas; quarto articulo com o colorido e a distribuição de pêlos igual a do terceiro e com $2 / 3$ do comprimento deste. Rostro reto, forte, castanho escuro, em repouso sob a face inferior da cabeça, que tambem tem colorido castanho escuro; o primeiro artículo rostral, revestido de pêlos dourados muito curtos, atinge o nivel da inserção do primeiro artíclilo antenal nos tubérculos anteniferos e é quase todo sulcádo superiormente para receber o labro, que é bem mais curto que o sulco; segundo articulo cerca de $1 \frac{1}{2}$ vez maior do que o primeiro, tambem revestido dos mesmos curtos pélos dourados; terceiro artículo curto, com cerca da metade do comprimento do primeiro, possuindo cerdas douradas esparsas mais longas e repousando no sulco proesternal que fica situado logo acima da inserção do primeiro par de patas.

Pescoço castanho escuro, con duas fáixas mais claras lateralmente.

Torax grande, principalmente representado por um pronoto e um escutelo bem desenvolvidos e pelas regiões inferiores, e laterais, pro-, meso- e metaesterno, pro-, meso- e inetapleura, com os escleritos delimitados.

Pronoto forte, de colorido castanho claro, nitidamente dividido nos dois lóbulos habituais por um sulco transversəl pouco acentuädo. O lóbulo anterior, que tem $1 / 4$ do comprimento total do pronoto, é provido de uma série de tubérculos e protuberâncias que o tornam muito típico. E' dividido medianamerite por um sulco longitudinal que se escava em uma fosseta ao nivel do bordo posterior do lóbulo anterior, ao lado do qual se situam duas bossas, de cada uma das quais se eleva um forte tubérculo de ápice arredondado e amarelado; estes tubérculos teem sua base contornada anteriormente por uma mancha pardoescura e posieriormente são prolongados por uma faixa amarelada e elevada cuja continuação constitue as carenas longitudinais; estão situados mais ou menos no meio do lóbulo. $\mathrm{Na}$ metade posterior deste lóbulo anterior estão situados quatro outros tubérculos de colorido amarelado, menos proeminentes: dois deles para trás e para fora das bossas acima descri. tas, reniformes, e os dois outros lateralmente, sobre os bordos laterais. Um outro tubérculo menos acentuado, em forma de barra, existe no bordo lateral do lóbulo anterior para diante deste último referido. De cada lado do colarinho, que não é muito pronunciado, existe tambem um tubérculo de ápice amarelado e base preta, pontudo e grande, dirigido cada qual para o lado do corpo, formando uma curva suave de concavidade anterior, de modo que o ápice se dirige para a linha mediana: são os ângulos anteriores do pronoto. Os hordos laterais do lóbulo anterior sâo percorridos por uma faixa preta que se prolonga até a metade do lóbulo posterior e o contorno do jordo aí é rugoso. O lóbulo anterior do pronoto é 


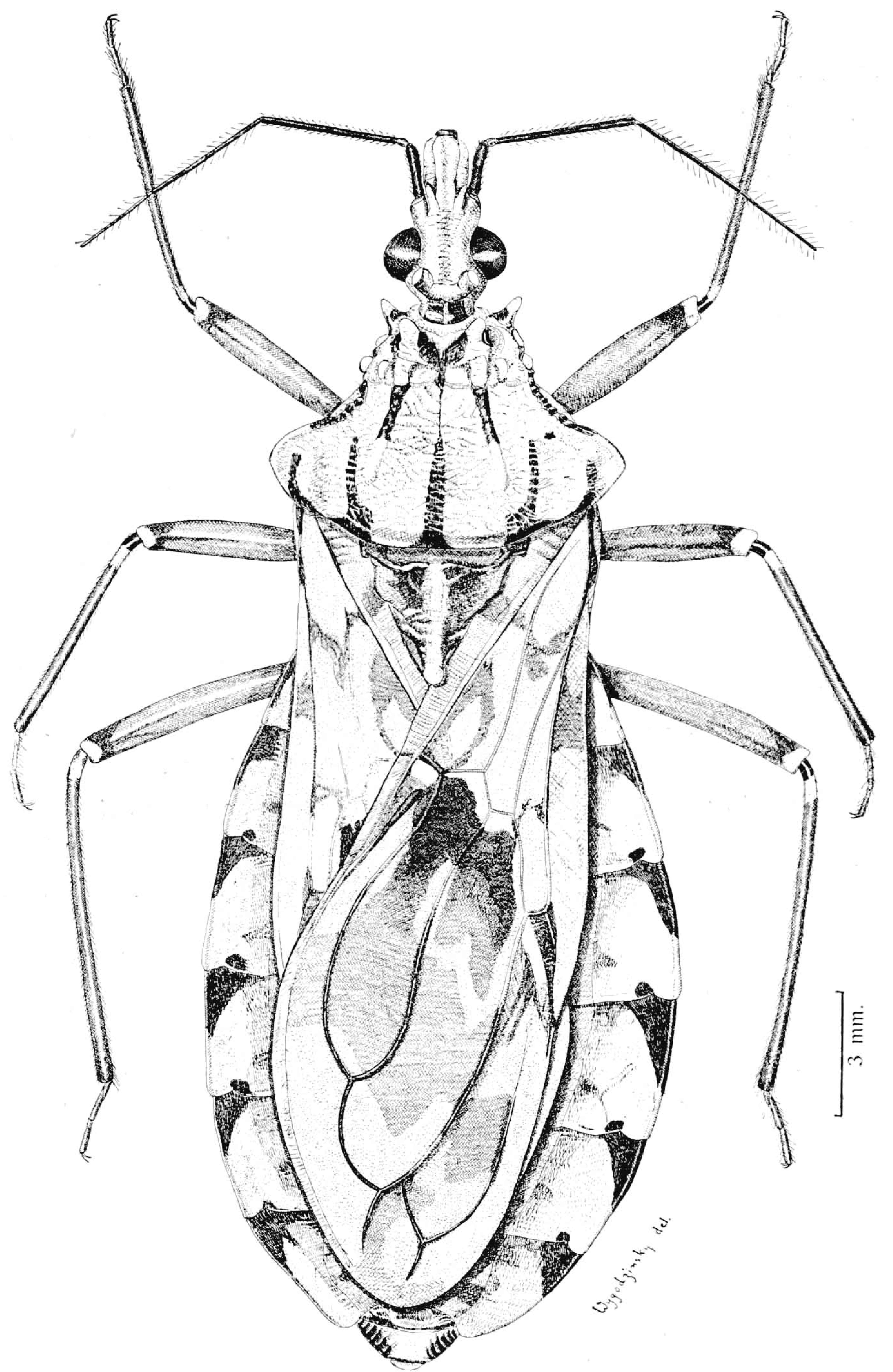

Fig. 1 - Panstiongyhus lignarius (WaLker. 1873), + , total. 
provido de pequenos pêlos dourados esparsos e zonas glabras distribuidas como na figura. O lóbulo posterior tambem possue raros pêlos dourados, mas tem o tegmento com pontuações e pequenas saliências e rugosidades. As duas carenas que nascem da base das bossas do lóbulo anterior terminam a pouca distância do bordo postericr do pronoto e são

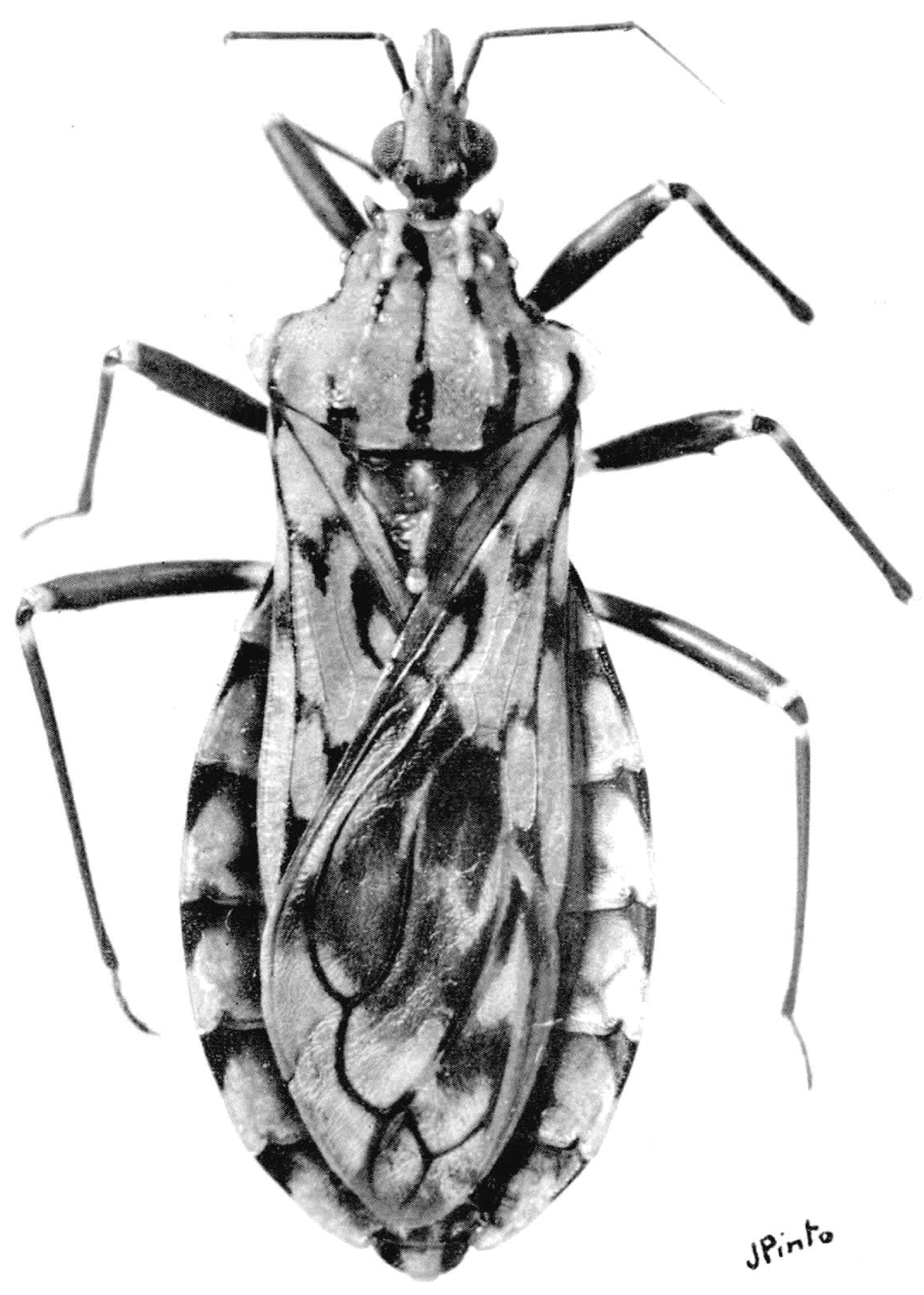

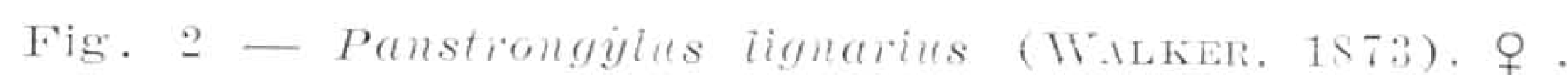

pretas na metade de sell comprimento a partir do sulco transversal que separa os dois lóbulos; cinco outras faixas pretas existem no lóbulo posterior do proncto, uma longitudinal mediana que vem do lóbulo anterior fina para se alargar posteriormente, e duas outras de cada lado, situadas a igual distância uma da outra, do meio do lóbulo posterior para trás, 
mai: dilatadas sobre os bordos, duas para fora das carenas e perto delas e duas sobre a saliência existente perto dos ângulos posteriores do pronoto, que são levemente elevados e refletidos.

Escutelo triangular com ápice arredondado e levantado, de cor escura e com uma fáxa mediana longitudinal amarelada, fracamente revestido de pêlos curtos; anteriormente, o escutelo possue, de cada lado, uma saliência de colorido castanho claro: o ápice é amarelado, globuloso, ligeiramente voltado para cima; na base e de cada lado existem duas pequenas saliências mamiliformes, de onde parte uma crista transversal para o centro do cscutelo que aí se deprime (depressão cordiforme).

Propleuras de colorido ocráceo medianamente, dos lados sendc de colorido negro: na parte póstero-lateral do proesterno a coloração ocrácea forma uma mancha ocrácea sepa rando a região escura de cada lado. Meso- e metapleuras castanho claro, com os escleritos delimitados por saliências negras. Na metapleura, quase cio nivel do inicio do abdome, existe, bem visivel, o segundo estigma torácico. No boráo postericr do proesterno e da propleura limitando com a mesoesterno e mesopleura, porem próximo à implantação do primeiro par de coxas, existem numerosas cerdas douradas reunidas em tufo. $O$ proesterno possue o sulco estridulatório escavado em forma de $\mathrm{V}$, delimitado anteriormente por pequená elevação lateral. Na porção mediana do mesoesterno existe uma saliência transversal bem acentuada, glabra, de colorido negro brilhante e $\mathrm{em}$ forma de lingueta. O nietaesterno é quadrangular, negro brilhante, com os quatro ângulos formando tubérculos. $O$ revestimento piloso destes segmentos é praticamente inexistente.

Hemi-élitros cobrindo quase todo o abdome, de colorido idêntico ao do pronoto, isto $\dot{\epsilon}_{\text {. }}$ castanho claro ou ocráceo com diversas manchas castanhas quer no cório, quer na mem. brana, cuja disposição é representada na figura. A membrana é cheia de pequenas ondu. lações irregulares, tem a base castanha escura, sendo muito nitidas as nervuras, que apre. sentam colorido castanho escuro e são ligeiramente mais claras no $1 / 3$ basal.

Patas de colorido geral castanho-ferrugineo, tendo, porem, os trocânteres e a base cos fêmures e das tíbias de coloração ocrácea. Primeiro par com dois espinhos bem salientes nos fêmures, paralelos transversalmente; o mesmo aspecto se encontra no segundo par. enquanto no terceiro par existe um pequeno tubérculo com uma cerda curta no ápice. Tibias dos primeiro e segundo pares praticamente do mesmo comprimento; a tíbia do terceiro par é a mais longa; todas são de colorido castanho escuro, ferrugineo, porem com a base negra seguida imediatamente de um estreito anel ocráceo e o ápice tambem negro, e são mais pilosas do que os fêmures, principalmente na face interna, as do primeiro e segundo pares possuindo fossetas esponjosas. Tarsos com três artículos, de colorido castanho escuro, com o terceiro artículo mais longo, onde se insere o par de unhas. O revestimento piloso das patas não é muito acentuado, só se tornando mais intenso nas tibias c tarsos.

Abdome con conexivo largo, de cor ocrácea e manchas escuras mais ou menos triangulares dispostas no ângulo-externo de cada segmento. No bordo posterior dos terceiro, quarto, quinto e sexto segmentos do conexivo existe uma reentrância como se fosse um corte, que se superpõe à mancha triangular, e acima da qual si assesta pequena mancha escura. Visto pela face inferior, os segmentos do conexivo possuem uma mancha preta com o bordo posterior de concavidade posterior, situada no $1 / 3$ anterior de cada segmento. Os segmentos abdominais são castanho escuros no centro e avermelhados (ferrugíneos) lateralmente; os bordos laterais são enegrecidos. Orifícios estigmáticos muito nítidos, bem arredondados, salientes e localizados junto da margem, no meio de cada segmento, de colo. ração ecrácea, formando contraste ccm o colorido geral. Mais na linha mediana, o abdome possue esparsos pêlos curtos e dourados e, aí, é levemente achatado. 
Ovipositor saliente, com uma larga mancha long̣itudinal mais pálida do que a coloração do conexivo, e quase sem pilosidade. Genitália do macho arredondada e, tambem, fra. camente pilosa.

Distribuição geográfica - Guiana Inglesa. Brasil e Guiana Holandesa. Os exemplares conhecidos sãe em número de 4: o tipo é macho e provem da Guiana Inglesa (segundo informação de China o tipo é do sexo femirino, mas a descrição de WALKER se refere a macho): outra fèmea da Guiana Inglesa, Esequibo River, Moraballi Creek, 20-10-929. Oxford University Expedition, det. por China, existe no Museu Britânico. Em nosso poder existem dois exemplares, que serviram de base à redescrição da espécie, com as seguintes indicações: † Piratuba, Abaeté, Estado do Pará, Brasil, Sege coll.: e ó Paramaribo, Charlesburg, Guiana Holandesa, 9-4-941, Geijskes coll. et leg.

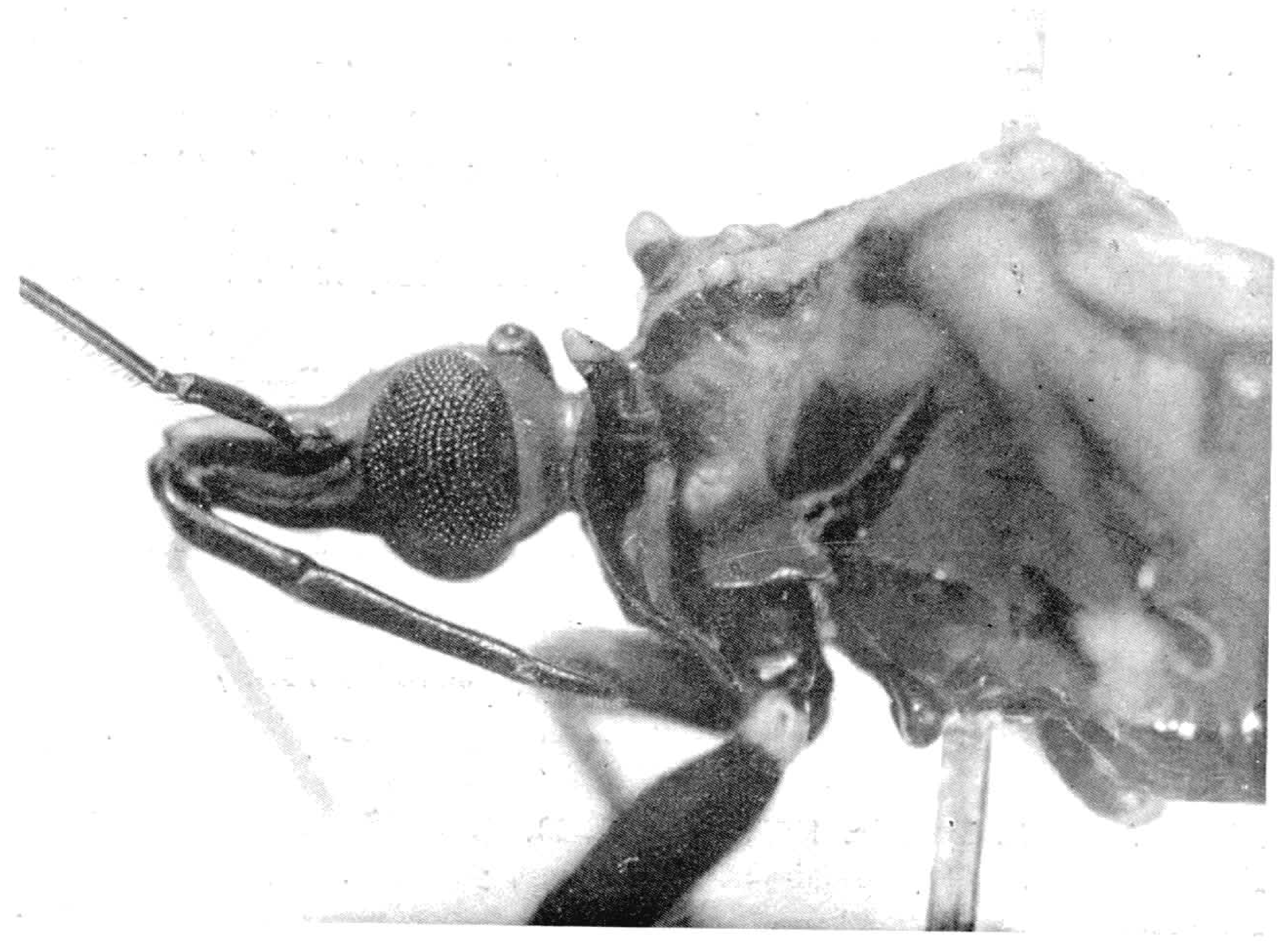

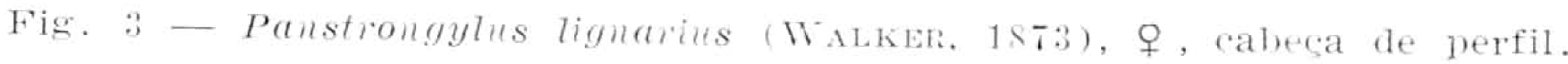

Esta espécie foi descrita em 1873 por Walker sob o nome de Conorhinus lignatius de um exemplar macho proveniente da Guiana Inglesa e ofertado por Sir R. Schomburgk ao Museu Britânico. Logo em 1896, Lethierry $\mathcal{E}$ Severin a catalogam no gênero Eratyrus sem qualquer explicação, naturalmente baseados no que diz WALKER em sua descrição original.

"This species has some affinity to Eratyrus in the rudimentary spines of the fore lobe of the prothorax"

o que é corrigido em 1899 por Champion que a considerava melhor colocada entre as espécies do gênero Lamus apesar de a referir ainda em Conorthinus 
A opinião de Champion foi aproveitada, em 1902, por Distant, até que Neiva, em 1911, e depois em 1914, transfere-a para o gênero Triatoma tendo examinado o exemplar tipo no Museu Britânico no qual verificou

"os ângulos posteriores do torax muito acentuados" e "as manchas ocraceas do conexivo mais largas do que as negras".

Em 1925, PInTo, apesar de referir a espécie no gênero Triatoma, acha que deveria ser incluida entre os Eratyrus pelo fato de possuir

"espinhos na parte anterior do pronoto".

Em 1930, Del Ponte publica os resultados de suas verificações no exemplar tipo existente no Museu Britânico e, com estas informações, Pinto em 1931, poude finalmente incluir a espécie em Panstrongylus, onde permanece.

Em 1939, Ulsinger, chama-a de Mestor lignarius, fazendo reviver o gênero de Kirkaloy indicado para substituir Lamus que se achava preocupado.

A té csta data, o único exemplar conhecido era o tipo, da Guiana Inglesa. Em 1940. entretanto, Costa Lima refere o achado da espécie em Piratuba, Estado do Pará, Brasil; o exemplar $q$ determinado por C. Lima serviu para a redescrição que publicamos.

Apezar de considerar Mestor como subgênero de Panstrongylus, Costa Lima denomina a espécie de $P$. lignatius. Lent E Pifano (1940) dão em quadro comparativo algumas informações sobre caracteres da espécie, a-fimde reforçar seus argumentos no sentido de estabelecer o gênero Mestor como sinônimo de Panstrongylus.

\section{Panstrongylus humeralis (USINGER, 1939)}

$$
\text { (Figs. 7-9) }
$$

Meslor humeralis Usinger, 1939, págs. 38-40.

Panstrongylus humeralis Lent \& Pifano, 1940, pág. 631.

Panstrongylus humeralis NeIva E LeNT, 1941, págs. 78, 92.

Em 1939, Usinger descreveu uma nova espécie, sob a denominação de Mestor humeralis, que se apresentava com caracteres extremamente parecidos aos de P. lignarius; o próprio autor acentua este fato ao pedir a CHINA que comparasse o holótipo $\delta$ de sua espécie com o da espécie de Walker. $\mathrm{O}$ conhecido hemipterologista inglês escreveu, então, o seguinte:

"At first sight your specimen appears to be identical with the unique type. Closer examination reveals the fact that it differs considerably in the structure and coloration of the pronotum and scutellum, particularly in the shape of the tubercles of the anterior lobe of the pronotum. The scutellum is also dark with a yellow median stripe in lignarius instead of yellow with a black median stripe as in your specimen. I have just found in our accessions another female spe- 
cimen of Mestor lignarius collected in British Guiana in 1929. There is some slight variation in the pronotal tubercles and coloration but in the main they are of the same pattern as in the type and quite distinct from your Panama specimen."
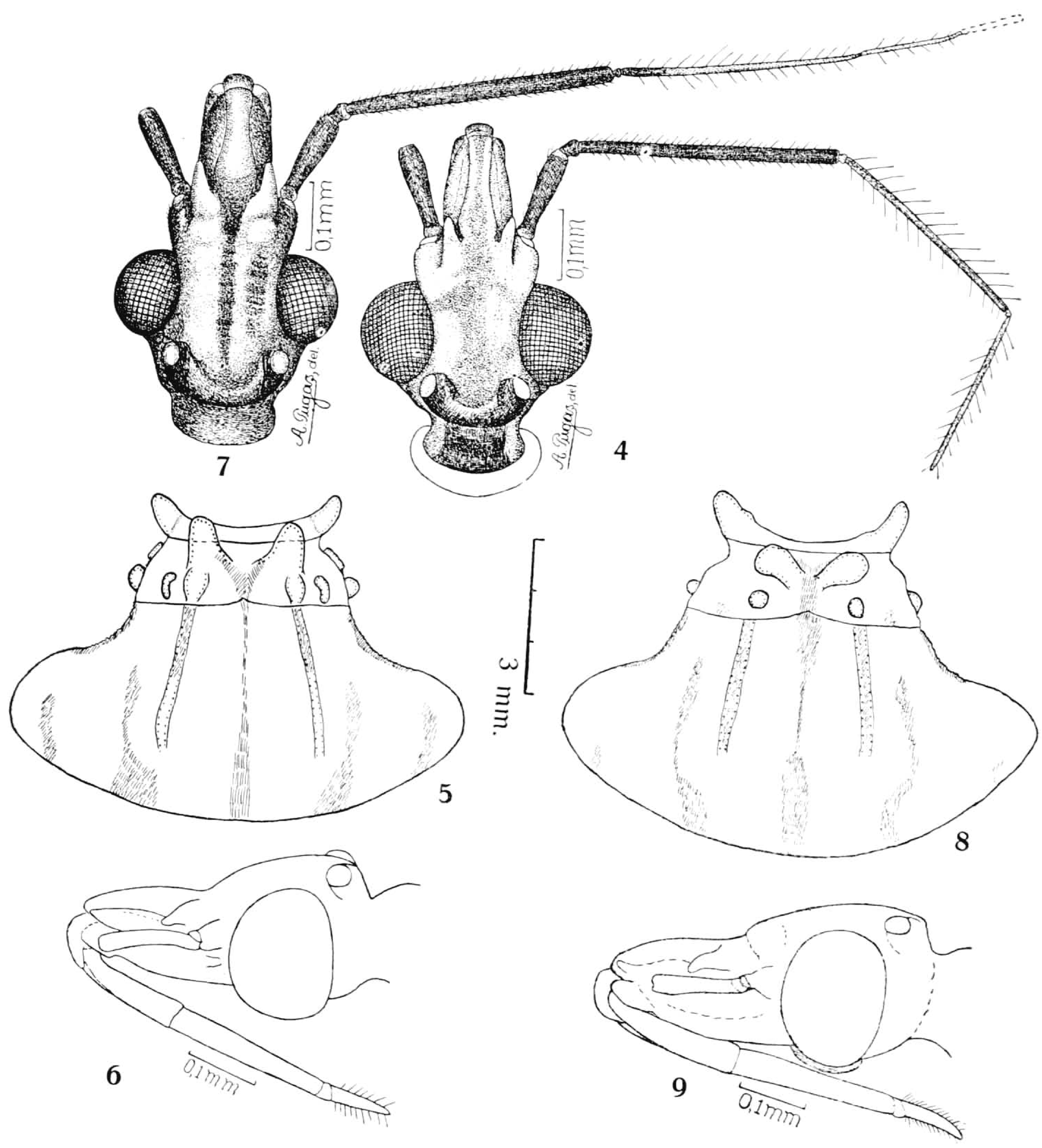

Panstrongylus lignarius (Walker, 1873), O - Fig. 4: Cabeça vista dorsal: fig. 5: pronoto; fig. 6: cabeça de perfil. Panstiongyhs humcralis (Usinger, 1939) o - Fig. T: Cabeca, vista dorsal; fig. 8: pronoto; fig. 9: cabeça, de perfil.

Por gentileza de Usinger pudemos estudar o alótipo \& desta espécie, rotulado Barro Colorado, C. Z., II/27, 1933, que pudemos comparar com nossos exemplares de $P$. lignarius e constatar as seguintes diferenças : 
Observado pela face superior, num exame macroscópico, o inseto é extremamente parecido com $P$. lignarius e tem colorido idêntico ao desta espé cie. O primeiro exame microscópico, com fraco aumento, logo revela que o revestimento piloso é muito mais intenso do que na espécie referida.

As diferenças principais residem, entretanto, no pronoto e no escutelo, a cabeça tambem possuindo certa distinção.

Pronoto - Lóbulo anterior com um par de saliências arredondadas anteriores ao lado do sulco mediano e outro par, menos elevado, atrás dos anteriores, ao nivel do bordo posterior do lóbulo, de onde nascem as carenas longitudináis; e, ainda, um tubérculo no bordo lateral de cada lado, situado ao nivel de uma linha que passasse, transversalmente, entre os dois pares de tubérculos acima referidos (fig. 8). Não existem os tubérculos situados ao nivel do bordo posterior do lóbulo mais para fora do início das carenas, que se vê em lignarius (fig. 5), e tambem não existe uma segunda saliência em barra do bordo lateral adiante do tubérculo que ai foi referido. Em compensação, os ângulos anteriores do pronoto são mais pronunciados e lamelados em $P$. humeralis do que em $P$. lignarius.

Escutelo - As principais diferenças residem numa inversão do colorido: enquanto em $P$. lignarius o escutelo possue uma faixa mediana longitudinal amarela contrastando com os lados pardo-escuros, em $P$. humeralis esta faixa central é escura e os lados amarelos; tambem a pilosidade é mais intensa nesta espécie, cuja escavação central cordiforme do escutelo é tambem mais pronunciada.

Cabeça - Um pouco mais alongada e com olhos menores em $P$. hume ralis (fig. 7), que tambem possue tubérculos parafrontais mais alongados do que em $P$. lignarius (fig. 4).

\section{REFERENCIAS BIBLIOGRÁFICAS}

Champion, G. C.

1899. Biologia Centrali-Americana. Insecta. Rhynchota. Hemiptera-Heteroptera, 2 : XVI + 416 págs., 22 ests. (ct pp. 206, 210).

Del Ponte, E.,

1921. Contribución al estudio del gen. Triatoma Lap., Rev. Inst. Bact. B. Aires, 3 (1) : 133 196, láms. 8-15.

Del Ponte, E.,

1930. Catálogo descriptivo de los géneros Triatoma Lap., Rhodnius Stal y Eratyrus Stal. Rev. Inst. Bact. Dep. Nac. Hig. B. Aires, 5 (8) : 855-937, figs. 1-25. láms. 41-53. 
Distant, W. L.,

1902. Rhynchotal Notes. - XIV. Heteroptera: Families Hydrometridae, Henicocephalidae, and Reduviidae (part.). Ann. Mag. Nat. Hist., 7, 10 (57) : 173-194,

HASE, A.,

1932. Becbachitungen an venezolanischen Triatoma-Arten, sowie zur allgemeinen Kenntnis der Familie der Triatomidae (Hemipt.-Heteropt.). Z. Parasitenk., 4 (4) : 585-652, figs. 1-27, 1 map.

Hussey, R. F.,

1922. A bibliographical notice on the reduviid genus Triatoma (Hemip.). Psyche. 29 (3) : 109-123.

LeNT, H. \& Pifano, F.,

1940. Sobre a identidade dos gêneros Panstrongylus Berg, 1879 e Mestor Kirkaldy, 1904. Redescrição de Panstrongylus rufotuberculatus encontrado, ra Venezuela, naturalmente infestado pelo Schizotrypanum cruzi. Rev. Ent., Rio de Janeiro, 11 (3) : 629-639, figs. $1-2$.

Lethierry, L. E Severin, G.,

1896. Catalogue géréral des Hémiptères, $3: 275$ pp., Berlin.

Lima, A. C.,

1940. Insetos do Brasil. Hemipteros, 2 : 351 pp., 446 figs., Rio de Janeiro.

NeINA, A.,

1911. Contribuição ao estudo dos hematófagos brasileiros e descrição de uma nova espécie de Triatoma. Brasil Med., 25 (46) : 461-462.

NeIVA, A.,

1914. Revisão do gênero Triatoma Lap., These, 80 pp., Rio de Janeiro.

NeIva, A. E LENT, H.,

1936. Notas e comentários sobre triatomídeos. Lista de espécies e sua distribuição geográfica. Rev. Ent., Rio de Janeiro, 6 (2) : 153-190.

Nenva, A. E Lent. H.,

1941. Sinopse dos Triatomideos. Rev. Ent., Rio de Janeiro, 12 (1/2): 61-92, figs. 1-28.

PINTO, C.,

1925. Ensaio monográfico dos reduvídeos hematophagos ou "barbeiros". These Fac. Med. Rio de Janeiro, 118 pp., figs. 1-58.

PiNto, C.,

1931. Valor do rostro e antenas na caracterização dos gêneros de Triatomídeos (Hemiptera, Reduvidioidea). Bol. Biol., $19: 45-136,70$ figs., 1 quadro.

Rodriguies, B. A. E Mello, G. B.,

1942. Contribuição ao estudo da Tripanosomiase Americana. Mem. Iint. Oswaldo Cruz, 37 (1): 77-90, ests. 1-2, figs. 1-8. 
Stal, C.,

1859. Monographie der Gattung Conorhinus und Verwandten. Berl. Ent. Z., 3 : 99-117, tab. 6, figs. I-IV.

STOLL, C.,

1788. Représentation exactement colorée d'après nature des Cigales et des Punaises, qui se trouvent dans les quatre parties du monde, l'Europe, l'Asie. l'Afrique et l'Amérique; rassemblées et décrites par Caspar Stoll, vol. 2 (Punaises), Amsterdam, 172 pp., 41 pls.

USINGER, R. L.,

1939. Descriptions of new Triatominae with a key to genera (Hemiptera, Reduviidae). Univ. Calif. Publ. Ent., 7 (3) : 33-56, pl. 1.

WALKER, F.,

1873. Catalogue of the specimens of Hemiptera Heteroptera in the collections of the British Museum. Part. 8, 220 pp., London. 